\title{
Erratum to: A High-Power Diode-Dynistor Generator for Gas-Discharge Technologies
}

\author{
S. V. Korotkov ${ }^{a, *}$ and A. L. Zhmodikov ${ }^{a}$ \\ ${ }^{a}$ Ioffe Physical Technical Institute, Russian Academy of Sciences, St. Petersburg, 194021 Russia \\ *e-mail: korotkov@mail.ioffe.ru \\ Received November 9, 2021; revised November 9, 2021; accepted November 9, 2021
}

DOI: $10.1134 / \mathrm{S} 002044122106021 \mathrm{X}$

The article "A High-Power Diode-Dynistor Generator for Gas-Discharge Technologies”, written by S. V. Korotkov and A. L. Zhmodikov, was originally published electronically in Springer-Link on 14 September 2021 without Open Access. After publication in volume 64, issue 5, pages 683-686 the authors decided to make the article an Open Access publication. Therefore, the copyright of the article has been changed to (C) The Author(s) 2021 and the article is forthwith distributed under the terms of a Creative Commons Attribution 4.0 International License (http://creativecommons.org/licenses/by/4.0/, CC BY), which permits use, duplication, adaptation, distribution and reproduction of a work in any medium or format, as long as you cite the original author(s) and publication source, provide a link to the Creative Commons license, and indicate if changes were made.

The original article can be found online at https://doi.org/10.1134/S0020441221050043 